Proceedings of the Annual Scientific Meeting of the International Medical Society of Paraplegia held at Heidelberg (Germany) on 3rd to 5th August 1972-Part I.

\title{
BLOOD FLOW IN MUSCLES OF PARAPLEGIC PATIENTS UNDER VARIOUS CONDITIONS MEASURED BY A DOUBLE ISOTOPE TECHNIQUE
}

\author{
By J. Seifert, G. Lob, E. Stoephasius, J. Probst and \\ W. BRENDEL \\ Institute for Surgical Research of the University of Munich and \\ Unfallkrankenhaus Murnau
}

PASsIve exercise of muscles is performed in paraplegic patients not only to prevent muscle contraction but also to improve the blood supply of the paralysed tissue. With regard to pressure sores it would be of great interest to know whether or not the blood flow of the surrounding muscle tissue could be increased by either passive movement or by the application of drugs. Therefore the blood flow of the anterior tibial muscle was investigated in patients with a complete lesion at LI after exercise and after the application of papaverin and compared with the blood flow of the intact biceps muscle.

Many different methods are described for the measurement of blood flow in muscles. Since Kety (1949) introduced the theoretical basis, the clearance of locally deposited indicators has been employed to determine blood flow in different tissues. Inert substances like the highly diffusable Xenon (Xe) referring to capillary blood flow or Cr-EDTA representing transport capacity are qualified as indicators, because they are quickly eliminated via either the lung or kidney. Radio-active isotopes of these substances can easily be detected by scintillation counter systems. Therefore radio-active ${ }^{133} \mathrm{Xe}$ and ${ }^{51} \mathrm{Cr}$-EDTA were used for the present study to investigate blood flow and capillary transport.

\section{MATERIALS AND METHODS}

Eight patients (Table) with a complete flaccid paralysis of the lower limbs, an injury of the thoracal or lumbar vertebra of more than 2 months' duration were selected. None were confined to bed so were able to move about in their wheelchairs.

Each patient was given six intramuscular injections, three into the biceps muscle of the forearm and three into the anterior tibial muscle of the contralateral leg. With the first injection blood flow and capillary transport was measured in both normal and paralysed muscle at rest. The second injection was given after active exercise of the brachial biceps muscle, i.e. movement against resistance 30 times and after passive movement of the anterior tibial muscle, i.e. movement of this muscle by a physiotherapist 30 times. The third and last injection was administered together with $4 \mu \mathrm{g}$ papaverin to stimulate blood flow by local vasodilation. 
TABLE

The Investigation of Muscle Blood Flow was performed in Eight Selected Patients with a complete Flaccid Lesion of the Lower Limb

\begin{tabular}{|c|c|c|c|c|}
\hline Patient & Age & Date of injury & Lesion & $\begin{array}{c}\text { Injured part of } \\
\text { spinal cord }\end{array}$ \\
\hline R.S. & 34 & 28.10 .7 I & Complete & LI \\
R.E. & $3 \mathrm{I}$ & $\mathbf{2 6 . 1 \mathrm { I } . 7 \mathrm { I }}$ & Complete & LI \\
A.S. & 45 & $9.10 .7 \mathrm{I}$ & Complete & LI \\
R.L. & 58 & $9.12 .7 \mathrm{I}$ & Complete & T6 \\
A.Z. & 28 & I.I.7I & Complete & TI2 \\
R.H. & 45 & $20.12 .7 \mathrm{I}$ & Complete & LI \\
H.B. & I8 & I2.4.72 & Complete & T6 \\
G.H. & $\mathbf{2 2}$ & $\mathbf{2 0 . 5 . 7 I}$ & Complete & T6 \\
\hline
\end{tabular}

measurement of blood flow through muscles

of spinal cord injured patients

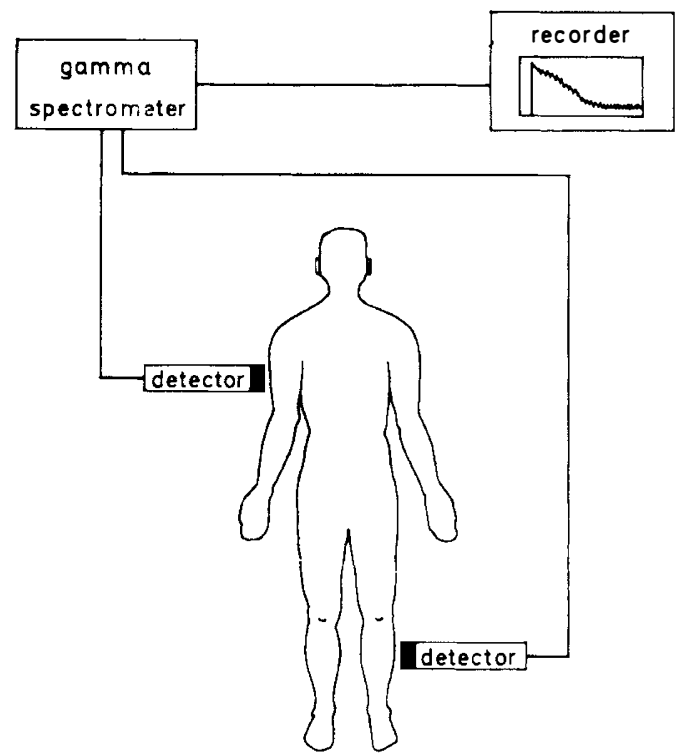

FIG. I

Blood flow and capillary transport of muscle biceps brachii and $\mathrm{m}$. tibalis ant. were measured after the local application of ${ }^{133} \mathrm{Xe}$ and ${ }^{51} \mathrm{Cr}$-EDTA. The clearance of both isotopes was observed by a 2channel Gamma spectrometer system.

After the i.m. application of $100 \mu \mathrm{Ci}{ }^{133} \mathrm{Xe}$ plus $30 \mu \mathrm{Ci}{ }^{51} \mathrm{Cr}$-EDTA (Fa. Buchler-Amersham) dissolved in $0.1 \mathrm{ml}$. physiological saline solution the disappearance rate of the isotopes was followed with a sodium crystal detector, as 
shown in Figure I. The scintillation detector was combined with a 2-channel spectrometer (Fa. Meditronik), the clearance of $\mathrm{Xe}$ as well as $\mathrm{Cr}-\mathrm{EDT}$ A registered logarithmically over one decade by common recorders. Blood flow and capillary transport respectively was calculated from the slope of the ${ }^{133} \mathrm{Xe}$ and ${ }^{51} \mathrm{Cr}-\mathrm{EDTA}$ clearances according to Renkin (I959) and Lewis (1972).

\section{RESULTS}

Six typical clearance curves from one patient after the injection of Xe are shown in Figure 2. Immediately after the injection, counts per minute increased to

blood flow through muscles of paraplegic patients measured with ${ }^{133} \mathrm{Xe}$

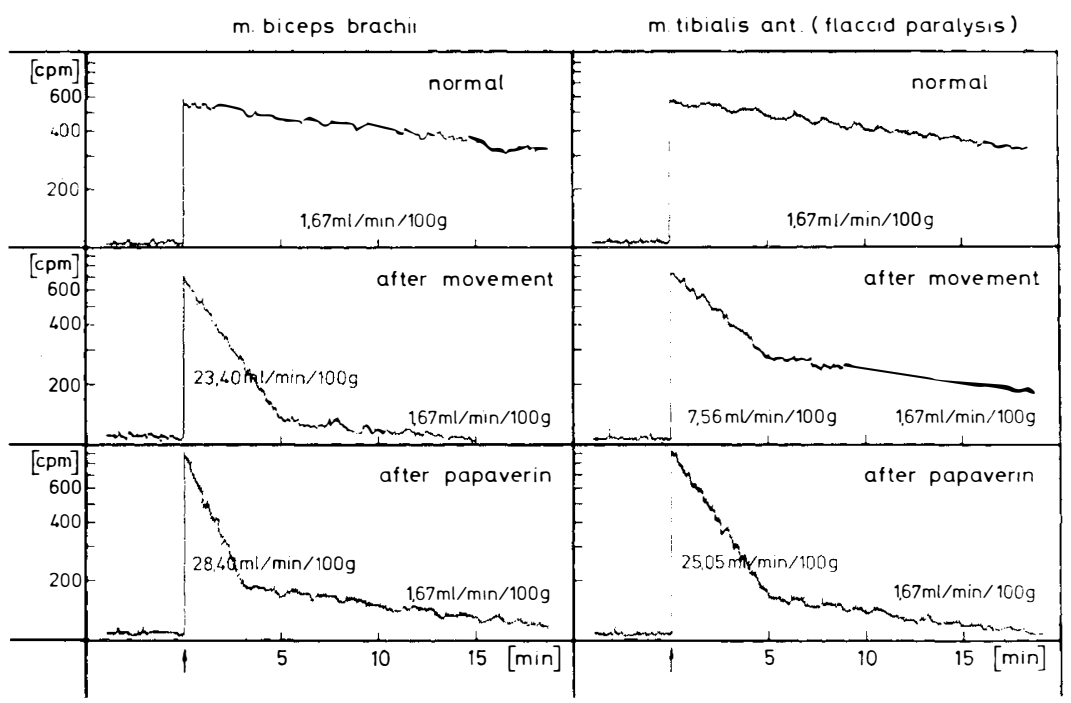

FIG. 2

The clearance curves of ${ }^{133} \mathrm{Xe}$ in normal and paralysed muscle of paraplegics after rest, exercise and papaverin.

maximum values and decreased depending on the capillary blood flow. The higher the capillary blood flow the faster an outwash of the isotope was measured. With this correlation the capillary flow of biceps muscle was found to be normal in this patient, $\mathrm{r} .67 \mathrm{ml} . / \mathrm{min} . / 100 \mathrm{~g}$ were given at the condition of rest. Active exercise increases this normal flow to values of $23.4 \mathrm{ml} . / \mathrm{min} . / \mathrm{IOO} \mathrm{g}$. Due to the application of papaverin the capillary blood flow can be increased to as much as $28.4 \mathrm{ml}$. $/ \mathrm{min}$. $/ \mathrm{IOO} \mathrm{g}$.

A similar phenomenon can be observed in a paralysed anterior tibial muscle. The elevation of blood flow after passive exercise, however, was measured to be only one-third of the increase of the biceps muscle of the same patient, whereas papaverin causes in paralysed muscles almost an equal blood flow increase to that of normal muscles. All blood flow measurements of normal and paralysed muscles were statistically analysed as shown in Figure 3. These data make it obvious that the blood flow of a resting paralysed muscle is significantly lower than that of a 
bloodflow in normal and paralysed muscles

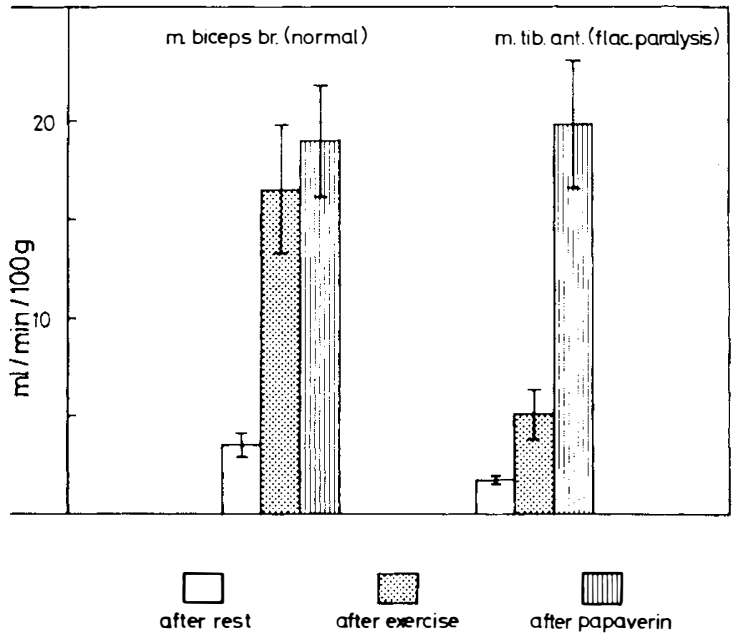

FIG. 3

The blood flow of $\mathrm{m}$. biceps brachii and $\mathrm{m}$. tibalis ant. in eight paraplegic patients after rest, exercise and papaverin.

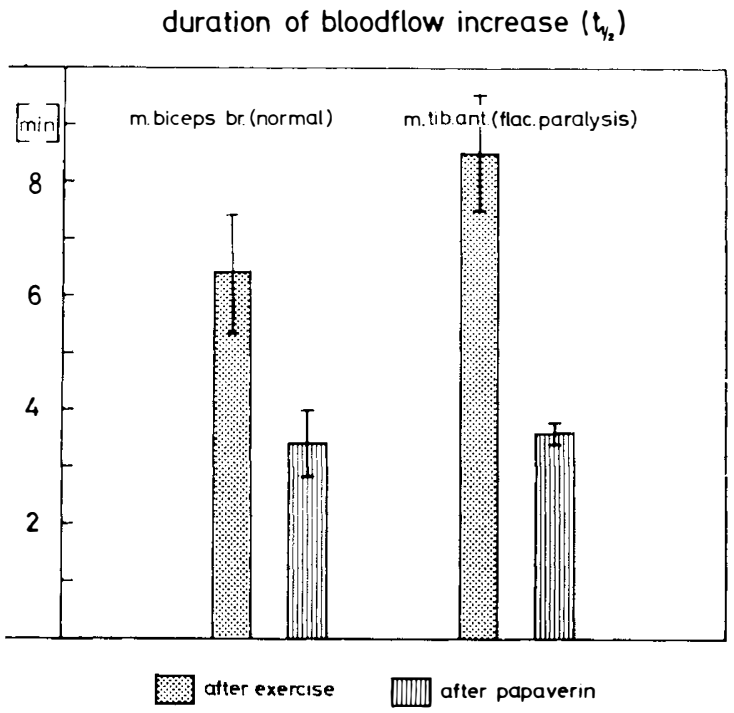

Fig. 4

The duration of blood flow and increase in normal and paralysed muscles after exercise and after papaverin. 
resting normal muscle, but even in paralysed muscles it can be raised by passive exercise to values twice as high as under normal conditions of rest. The highest increase, which is comparable with the increase in normal muscles, can be achieved with a simultaneous application of $4 \mu \mathrm{g}$ papaverin.

It is of great importance to produce not only a high increase of blood flow but also a long lasting effect. Therefore the time of blood flow increase was calculated (fig. 4). The duration of blood flow increase after papaverin lasts for only a short time in both normal and paralysed muscles, i.e. three minutes. After exercise, however, the increase of capillary blood flow lasts twice as long as after papaverin in normal muscles and nearly three times as long in paralysed muscles.

To quantify the effect of exercise or papaverin the increase of blood flow was multiplied with the time interval of action. This product is identical with the blood

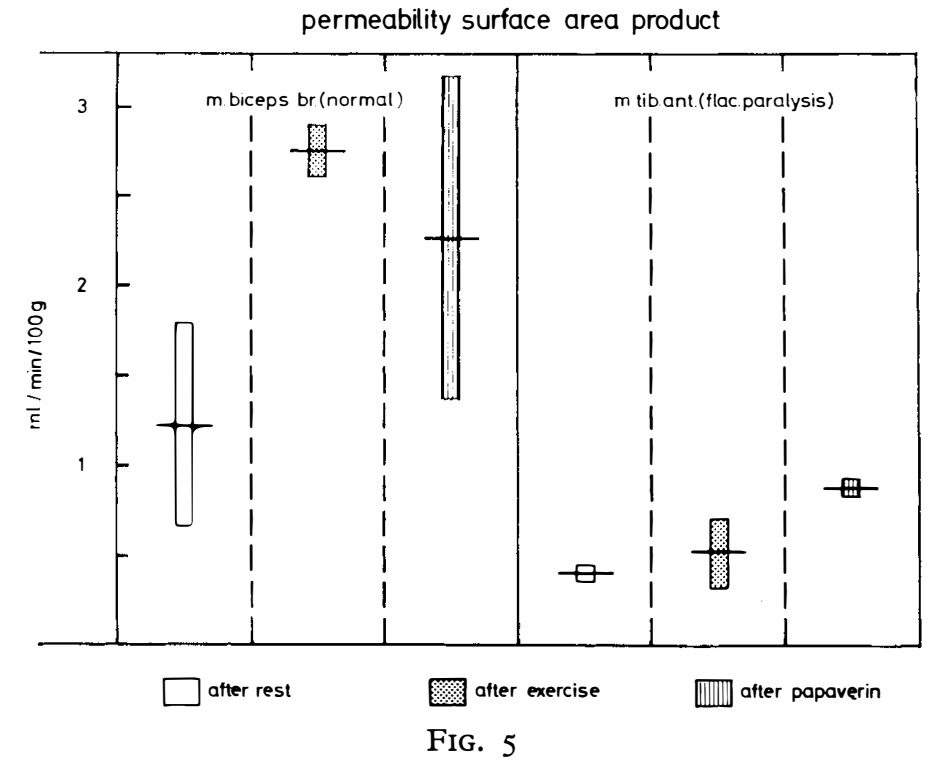

The capillary transport calculated by means of the permeability area surface product after rest, exercise and papaverin in normal and paralysed muscles.

which passed through the muscle during blood flow increase. By this calculation a very interesting correlation can be revealed: the normal biceps muscle was perfused with $100 \mathrm{ml} . / \mathrm{IO0} \mathrm{g}$. after exercise, but with only $65 \mathrm{ml} . / \mathrm{IOO} \mathrm{g}$. after papaverin. A reverse relation, however, was found in paralysed muscles. Although the blood flow increase after exercise lasts nearly three times as long as after papaverin the whole quantity of circulating blood during this time was calculated to be nearly twice as high after papaverin as after exercise. This means, that in paralysed muscles the effectivity of blood flow increase after papaverin was measured to be higher than after exercise.

For therapeutical consequences not only an effective blood flow increase is of great importance, but also an increase of the capillary transport capacity. To get an idea of this, all eight patients received ${ }^{51} \mathrm{Cr}-\mathrm{EDT} A$ together with ${ }^{133} \mathrm{Xe}$. From the disappearance of ${ }^{51} \mathrm{Cr}-\mathrm{EDTA}$ the so-called permeability surface area product can 
be calculated, which is representative for the capillary transport (fig. 5). It is evident that in normal biceps muscle the capillary transport is significantly increased after exercise. Papaverin also increases capillary transport in normal muscle from $\mathrm{I} \cdot 2 \mathrm{ml} . / \mathrm{min}$./IO0 g. to $2 \cdot 2 \mathrm{ml}$. $/ \mathrm{min}$./ $100 \mathrm{~g}$. this difference however is statistically insignificant.

In paralysed muscles all values are lower than in normal muscle. But the exercise as well as the application of papaverin results in an increase of capillary transport. With regard to the local values in paralysed muscles at rest the increase amounts to nearly Ioo per cent. and is comparable to the increase in normal muscle. This data indicates that the capillary transport can be activated by exercise and papaverin in not only normal, but also in paralysed muscles.

\section{DISCUSSION}

Nutritional blood flow in the paralysed anterior tibial muscle of paraplegics was found to be significantly lower than in normal biceps muscle of the same patient. Consequently there must be regions in these patients which perfused quite normally but also regions which have decreased the circulation of blood. Measuring the blood volume or the circulation time with the indicator dilution principle these two factors must be taken into consideration, because the complete mixing of the tracer is delayed under those physiopathological conditions.

Blood flow increase can be achieved in flaccid paralysed muscles either by exercise or by the local application of papaverin. While the duration of blood flow increase lasts longer after exercise the effective perfusion was calculated to be twice as high after papaverin as after exercise. Whereas papaverin i.m. applicated causes this increase only in a very small region, passive exercise elevates the blood perfusion in the whole muscle. Therefore the use of papaverin is not the substitution of passive exercise but perhaps the stimulation of the healing process of therapy-resistant pressure sores by a local application into the wound.

The surrounding tissue of pressure sores contains a lot of high molecular substances, which delay the healing process. If there were any drug or physiotherapeutical exercise that would accelerate the transport of such metabolites from the tissue to the bloodstream, pressure sores would possibly heal in a shorter time. The measurement of the capillary transport with ${ }^{51} \mathrm{Cr}-\mathrm{EDTA}$ indicates that the increase of blood flow in paralysed muscles is combined with a Ioo per cent. increase of capillary transport. These findings support the practical experience that the better the blood supply the better the capillary transport of metabolites and the better the chances for the healing process of wounds can be expected. Therefore, it seems to be worthwhile to stimulate the healing of therapy-resistant pressure sores by either regular passive exercise or the local application of papaverin.

\section{SUMMARY}

Blood flow of normal biceps and flaccid paralysed anterior tibial muscle was measured in eight patients by means of ${ }^{133} \mathrm{Xe}$ and ${ }^{51} \mathrm{CrEDTA}$ clearance. Exercise as well as papaverin could increase the blood flow significantly in both muscles. Whereas the duration of blood flow increase was found to last longer after exercise the effective perfusion was calculated to be twice as high after papaverin as after exercise in paralysed muscles. Together with the elevation of capillary blood flow 
a Ioo per cent. increase of capillary transport can be observed. From this data the conclusion can be drawn that passive exercise and the local application of papaverin increases capillary blood flow and transport capacity possibly resulting in a faster healing of chronic pressure sores.

\section{REFERENCES}

KETY, S. S. (1949). Measurement of regional circulation by the clearance of radioactive sodium. Amer. Heart F. 38, 32 I.

LEwis, D. H. (I972). Measurement of capillary flow and capillary transport. In Hemodilution. Theoretical Basis and Clinical Application (Ed. Meßmer, K. \& SchmidSchönbein, H.). Basel-München-Paris, London, New-York, Sydney: S. Karger.

Renkin, E. M. (I959). Transport of potassium-42 from blood to tissue in isolated mammalian skeletal muscles. Amer. F. Physiol. 197, 1205. 